\title{
TRICKLE DOWN THEORY SEBAGAI DASAR MOTIVASI MAHASISWA MELAKUKAN POLYTECHNIC SOSIAL RESPONSIBILITY
}

\author{
Tetty Rimenda ${ }^{1)}$, R. Elly Mirati ${ }^{2)}$ \\ ${ }^{1}$ Jurusan Akuntansi, Politeknik Negeri Jakarta Nama Fakultas, \\ email: rimenta@yahoo.com \\ ${ }^{2}$ Jurusan Akuntansi, Politeknik Negeri Jakarta. Nama Fakultas, \\ email: ellymirati@yahoo.co.id
}

\begin{abstract}
Initially CSR activities were known as corporate activities to pay attention to their environment. Further developments in CSR were also carried out at the University. This study discusses the CSR activities at the Jakarta State Polytechnic Social Responsibility, whose implementation is carried out through AGTV. This AGTV activity has been held for 6 years in Lio Depok Village. The problem faced is the lack of interest of volunteers to help implement this AGTV activity. The purpose of this study was to examine the effect of Trickle Down Theory which has been widely used in the field of fashion and promotion of the motivation to implement AGTV. Respondents were volunteers from the Jakarta State Polytechnic Accounting Department who carried out the Polytechnic Social Responsibility program. Data is processed by SPSS regression analysis. The results prove that Trickle Down and Trickle Up do not influence motivation in carrying out CSR activities, but the Trickle Round which is an attachment between volunteers influences the implementation of CSR carried out in AGTV
\end{abstract}

Keywords: CSR, Trickle Down Theory, Trickle Round.

\section{PENDAHULUAN}

Corporate Social Responsibility (CSR) telah menjadi fenomena global untuk menyelesaikan masalah sosial, lingkungan dan ekonomi dengan tujuan untuk meningkatkan manfaat bagi masyarakat.

Awalnya CSR dilaksanakan oleh perusahaan sebagai bentuk tanggung jawab sosial terhadap masyarakat. Dana CSR dialokasikan dari sebagian keuntungan perusahaan yang di kembalikan kepada masyarakat. Ada berbagai definisi tentang CSR yang sering digunakan, tetapi yang paling sering dipakai adalah tanggung jawab sosial perusahaan yang mencakup bidang ekonomi, hukum dan etika Carroll, (1999), dengan demikian CSR mencakup berbagai perilaku, seperti bersikap ramah terhadap karyawan (employee friendly), ramah lingkungan (environment friendly), memperhatikan etika (mindful of ethics) dan menghormati masyarakat dimana pabrik perusahaan berlokasi Tariq Khan (2012)

Perkembangan selanjutnya CSR bukan hanya dilaksanakan oleh perusahaan tetapi sudah dinisiasi oleh banyak pihak. Salah satunya oleh pemerintah, dimana Pemerintah menjadi penggerak dari kegiatan CSR agar tidak sekedar menjadi kegiatan philantropis saja, tapi dapat memotivasi masyarakat agar dapat menolong dirinya sendiri (Moon, 2004). Menurut Matten \& Moon (2008), kegiatan dan pelaksanaan CSR berbeda-beda antar negara dipengaruhi oleh faktor budaya di masing-masing negara tersebut. Perkembangan selanjutnya CSRditerapkan di Universitas. Universitas bertanggung jawab terhadap kelangsungan masyarakat 
dimasa dating, untuk itu sejak dari masa kuliah, mahasiswa sudah diwajibkan untuk perduli terhadap lingkungan dan masyarakat, sehingga kegiatan universitask pun diarahkan untuk membantu masyarakat sekililingnya. Berdasarkan penelitiannya itu maka Ahmad (2012) mengusulkan agar kegiatan CSR di Universitas disebut dengan USR (University Social Responsibility). Selain itu Ahmad (2012) mengatakan bahwa kegiatan USR akan berhasil bila pihak Universitas bekerja sama dengan perusahaan.

Politeknik sebagai Lembaga Pendidikan tidak terlepas dari kewajiban untuk mengerakkan kegiatan CRS di lingkungan Politeknik. Dengan dana penelitian yang diterimanya maka Politeknik dapat menggunakannya untuk pelaksanaan CSR dalam bentuk Pengabdian Kepada Masyarakat. Dilaksanakan multi tahun atau hanya pada tahub berjalan. Biasanya dalam pelaksanaannya kegiatan itu melibatkan mahasiswa. Selain kegiatan pengabdian yang dilakukan oleh dosen, mahasiswa juga mempunyai kegiatan pengabdian kepada masyarakat yang pada penelitian ini disebut sebagai Politechnic Social Responsibility (PSR).

Mahasiswa Jurusan Akuntansi Politeknik Negeri Jakarta yang tergabung dalam HMJA (Himpunan Mahasiswa Jurusan Akuntansi) mengadakan program PSR dengan berbagai cara, antara lain AGTV (Accounting Goes To Village), Akuntansi Peduli. Anjangsana Sosial dan lain-lain yang tujuannya adalah untuk meningkatkan keperdulian mahasiswa terhadap masyarakat.

Dari berbagai kegiatan PSR yang dirancang oleh mahasiswa jurusan akuntansi, AGTV adalah kegiatan yang paling lama bertahan. Kegiatan ini sudah berjalan sejak tahun 2013 sampai saat ini. Kegiatannya berupa mengajar anak-anak kelas 1 - 6 SD dengan materi Matematika, IPA, IPS,Agama, Bahasa Inggris dll. Kegiatan ini dilaksanakan di masjid
Unwanussa'adah kampung Lio Depok. Kampung Lio adalah kampung tua yang awalnya adalah tempat pembakaran tanah liat. Lokasinya dekat dengan Situ Rawa Besar yang diyakini memiliki kualitas tanah yang baik untuk membuat gerabah. Kampung ini padat penduduk dengan gang-gang sempit bak labirin. Kondisi perekonomian penduduknya dari kelompok bawah, sehingga pendidikan anak-anak mereka pun sangat terbatas. Kondisi inilah yang membuat mahasiswa jurusan akuntansi terdorong untuk membantu mengajar anak-anak tersebut dalam kegiatan AGTV.

Permasalahan yang dihadapi oleh penggerak AGTV adalah rendahnya minat mahasiswa jurusan Akuntansi untuk ikut menjadi sukarelawan dalam melakukan PSR. Alasan rendahnya minat untuk melaksanakan PSR adalah karena perkuliahan di PNJ cukup menyita waktu. Adanya system DO membuat mereka khawatir bila mengikuti terlalu banyak kegiatan dapat membuat mereka di DO. Selain itu sulitnya izin orang tua untuk menjadi sukarelawan. Sehingga jumlah sukarelawan yang mengajar di PSR ini sangat terbatas. Selain faktor-faktor yang disebutkan diatas, diduga kurangnya minat mahasiswa menjadi relawan adalah karena kurangnya role model atau panutan yang melakukan PSR.

Menurut Kolk, Van Dolen \& Vock (2010) suksesnya pelaksanaan kegiatan CSR karena pelaksanannya dilakukan secara Trickle Down (dari atas kebawah misalnya dari management ke pekerja), Trickle Up (dari bawah ke atas misalnya dari pekerja ke manajemen) dan Trickle Round (role model diantara sesama pekerja). Ketiga metode diatas akan mendorong sukses tidaknya pelaksanaan CSR.

Sehubungan dengan teori tersebut diatas maka penelitian ini akan menguji pengaruh metode role model sesama mahasiswa terhadap kegiatan PSR sesuai dengan teori Trickle Down Theory khususnya Trickle Round. Hasil penelitian 
Tetty Rimenda \& R. Elly Mirati, Trickle Down Theory Sebagai Dasar Motivasi...

diharapkan dapat mengatasi permasalahan kurangnya minat mahasiswa dalam melakukan kegiatan PSR. Dan dapat menjadi role model dalam pelaksanaan Polytechnic Social Responsibility

\section{KAJIAN LITERATUR DAN PENGEMBANGAN HIPOTESIS}

\section{CSR - USR -PSR}

Vasilescua, Barnab, Epurec, Baicud (2010) menjelaskan terjadinya pergeseran makna dari Corporate Social Responsibility (CSR). CSR bukan hanya sekedar kegiatan philantrophi, tetapi lebih kepada bagaimana memotivasi masyarakat untuk lebih memperhatikan lingkungannya. Lembaga yang paling dekat untuk menanamkan nilai-nilai itu adalah lembaga pendidikan, salah satunya adalah Universitas. Sehingga ada kecenderungan Corporate Social Responsibility (CSR) sudah bergeser ke University Social Responsibility (USR). Tanggung jawab Universitas bukan hanya mengeluarkan ijazah, tetapi universitas juga mempunyai kewajiban untuk menanamkan nilai-nilai social kepada mahasiswanya.

Penelitian ini akan meneliti kegiatan sosial yang dilakukan oleh mahasiswa di Politeknik, khusunya di Jurusan Akuntansi Politeknik Negeri Jakarta, sehingga dengan demikian kami menyebut kegatan yang dilakukan tersebut sebagai Polytechnic Social Responsibility (PSR)

\section{Trickle Down Theory}

Teori yang mendasari penelitian ini adalah Trickle Down Theory yang diaplikasikan dari bidang fashion, dimana orang akan meniru atau mengikuti gaya berpakaian atau model pakaian orang yang dianggap mempunyai pengaruh. (Miller, Mc Intyre \& Mantrala ; 1993). Proses adopsi fashion dapat dilihat dari berbagai sudut pandang, misalnya sebagai proses top-down (trickle down) dari kelompok social ekonomi yang lebih tinggi kepada kelompok sosial ekonomi yang lebih rendah (contohnya busana mewah pada awalnya hanya dapat dikenakan oleh kelompok atas tetapi lama kelamaan diadopsi oleh kelompok ekonomi bawah ketika harga fashion itu turun).

Ketika Trickle Down Theory diaplikasikan kepada PSR, dalam hal ini kegiatan social AGTV oleh mahasiswa jurusan akuntansi, maka diperlukan contoh atau role model dari kelompok yang statusnya dalam organisasi lebih tinggi untuk melakukan kegiatan sosial sehingga kegiatan mereka itu akan diadopsi oleh kelompok yang statusnya dalam organisasi lebih rendah. Sehingga hipotesis yang diajukan adalah :

H1 : Keikutsertaan pengurus HMJA sebagai sukarelawan dalam acara AGTV berpengaruh positif terhadap kegiatan AGTV

Sebaliknya adopsi fashion bottom-up (trickle up) terjadi ketika pakaian kelompok bawah yang pada akhirnya diadopsi oleh kelompok atas, Misalnya jeans pada awalnya hanya dikenakan kelompok kelas pekerja, tetapi secara bertahap diadopsi oleh kelas sosial yang lebih tinggi.

Ketika kondisi ini diaplikasikan kepada kegiatan PSR dalam hal ini kegiatan AGTV, dimana dalam kurun waktu 6 tahun, sering sekali terjadi kondisi dimana pengurus HMJA pun merasa jenuh untuk menjadi sukarelawan di acara AGTV ini. Hal itu disebabkan oleh banyak hal, terutama masalah kesulitan mencari dana untuk kegiatan ini. Dalam hal ini sukarelawan yang non pengurus tetapi sudah lama mengajar AGTV mempunayai komitmen yang tinggi. Merekalah yang memberi contoh kepada pengurus untuk tetap bertahan

Kondisi ini sesuai dengan Mirvis (2012) yang mengatakan bahwa dalam pelaksanaan CSR, komitmen adalah faktor 
yang mendominasi keberlangsungan pelaksanaan CSR. Sehingga hipotesis yang diajukan adalah :

H2 : Komitmen sukarelawan untuk keberlangsungan AGTV berpengaruh positif terhadap kegiatan AGTV.

Selain top-down dan bottom-up, proses adopsi fashion juga dilakukan oleh sesama kelompok ekonomi, dimana mereka akan mengadopsi fashion yang mereka anggap mewakili kelompoknya. Hal ini sesuai dengan Mc Cracken (1986) mengatakan bahwa fashion adalah proses mengadopsi simbol yang memberi identitas kepada seseorang. Proses fashion selalu berhubungan dengan faktor budaya yang dianut oleh sekelompok orang tertentu. Sehingga proses adopsi fashion trickle round terjadi pada .kelompok sosial ekonomi yang sama.

Ketika kondisi ini diaplikasikan kepada kegiatan AGTV, maka kebersamaan sukarelawan dan pengurus HMJA meningkatkan motivasi mereka dalam melaksanakan kegiatan social AGTV. Sehigga hipotesis yang diajukan adalah :

H3 : Kebersamaan antara sesama sukarelawan berpengaruh positif terhadap kegiatan AGTV

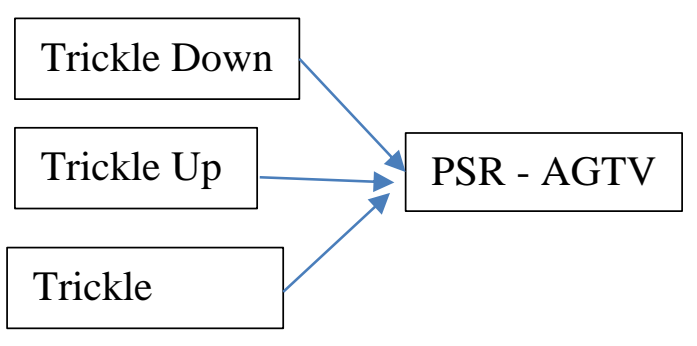

\section{METODE PENELITIAN}

Metode penelitian yang digunakan adalah metode kuantitatif ,dengan cara menyebarkan kuesioner kepada mahasiswa Politeknik Negeri Jakarta yang ikut serta dalam kegiatan AGTV. Jumlah responden 35 orang, yaitu pengurus
AGTV dan anggota HMJA yang sering mengikuti acara PSR.

Populasinya responden adalah semua anggota HMJA. Sedangkan yang menjadi responden berjumlah 35 orang. Untuk kemudahan memilih responden, maka metode yang dipakai untuk memilih responden adalah dengan cara convenience sampling. Yaitu semua mahasiswa HMJA yang ada di kampus sewaktu proses penyebaran kuesioner berlangsung.

Setelah kuesioner diisi dan dikembalikan oleh responden, maka langkah selanjutnya adalah mencari informasi yang lebih detail lagi dengan cara melakukan wawancara terhadap responden. Topik wawancara lebih kepada alasan detail dan motivasi mahasiswa dalam melaksanakan kegiatan PSR salah satunya yang berhubungan dengan kegiatan AGTV. Selain itu ditanyakan juga secara detail peran role model teman sebaya (trickle round) terhadap motivasi mahasiswa untuk melaksanakan kegiatan social.Pengolahan data dengan menggunakan SPSS Analisa regresi berganda

\section{HASIL DAN PEMBAHASAN}

Kegiatan PSR dalam bentuk AGTV sudah dilaksanakan selama 6 tahun secara berturut-turut. Tempat kegiatan ini juga sejak awal diadakan di RW 13 Kampung Lio, Kelurahan Depok. Letak Kampung Lio ini sangat strategis karena berada di pusat kota Depok. Kampung Lio juga mengelilingi bantaran Setu Rawa Besar. Kegiatan AGTV adalah dengan mengajar anak-anak usia SD, ( kelas 1- 6 ) Kegiatan AGTV ini bersifat rutin yang dilaksanakan setiap hari sabtu.

Jumlah relawan yang secara bergantian melakukan kegiatan mengajar anak-anak di kampung Lio sejumlah 30 orang, dengan topik : Matematika, IPA, IPS, Bahasa Inggris, Bahasa Indonesia, Agama. Selain pelajaran formal, mereka juga mengajarkan pengetahuan informal seperti 
Tetty Rimenda \& R. Elly Mirati, Trickle Down Theory Sebagai Dasar Motivasi...

membuat cendera mata dari barang bekas yang banyak terdapat didaerah mereka, mewarnai gerabah yang menjadi mata pencaharian orang tua mereka.

Dari 35 kuesioner yang disebarkan kepada responden, semuanya kembali dan diolah dengan menggunakan SPSS 23 analisis regeressi berganda. Hasil uji sbb :

\begin{tabular}{|c|c|c|c|c|c|}
\hline Model & $\begin{array}{l}\text { Sum of } \\
\text { Squares }\end{array}$ & df & $\begin{array}{l}\text { Mean } \\
\text { Square }\end{array}$ & $\mathrm{F}$ & Sig. \\
\hline 1 Regression & 449.920 & 3 & 149.973 & 6.440 & $.002^{b}$ \\
\hline Residual & 721.966 & 31 & 23.289 & & \\
\hline Total & 1171.886 & 34 & & & \\
\hline
\end{tabular}

a. Dependent Variable: AGTV

b. Predictors: (Constant), TRound, TDown, TUp

Dari uji ANOVA terlihat bahwa, TDown, TUp dan TRound mempengaruhi AGTV. Dengan kata lain bahwa Keikut sertaan pengutus HMJA, Komitmen sukarelawan dan kebersamaan sesame relawan secara Bersama-sama memberi pengaruh positif terhadap kegiatan AGTV

\begin{tabular}{|c|c|c|c|c|c|}
\hline \multicolumn{6}{|l|}{ Coefficients $^{a}$} \\
\hline \multirow[b]{2}{*}{ Model } & \multicolumn{2}{|c|}{$\begin{array}{l}\text { Unstandardized } \\
\text { Coefficients }\end{array}$} & $\begin{array}{l}\text { Standar } \\
\text { dized } \\
\text { Coeffici } \\
\text { ents } \\
\end{array}$ & \multirow[b]{2}{*}{$t$} & \multirow[t]{2}{*}{ Sig } \\
\hline & B & Std. Error & Beta & & \\
\hline 1 (Constant) & 25.562 & 4.821 & & 5.303 & .000 \\
\hline TDown & .250 & .154 & .346 & 1.625 & .114 \\
\hline TUp & -.158 & .179 & -.204 & -.882 & .385 \\
\hline TRound & .439 & .142 & .533 & 3.091 & .004 \\
\hline
\end{tabular}

a. Dependent Variable: AGTV

Tetapi bila dilihat koefisen $\mathrm{T}$ Down tehadap AGTV 0,114>0,05, maka T Down tidak mempangaruhi AGTV (H1 ditolak) Begitu juga koefisien $\mathrm{T}$ Up terhadap AGTV 0,385 > 0,05 (H2 ditolak) Hanya TRound yang memiliki koefisen regeresi $0,004<0,05$ (H3 diterima)

\section{KESIMPULAN}

Hasil penelitian ini menyimpulkan bahwa Trickle Down Theory terbukti mempengaruhi motivasi dalam melaksanakan AGTV. Hasil ini memperkuat Kolk, Van Dolen \& Vock (2010) yang mengatakan bahwa teoriTrickle Down yang berasal dari ranah fashion dapat diterapkan pada ranah CSR.

Selanjutnya disimpulkan pula bahwa Trickle Round yang paling mempengaruhimelaksanakan AGTV . DEngan kata lain, kebersamaan antar sesama relawan, kerjasama dan komitmen mereka sangat mempengaruhi keberlangsungan AGTV ini. Hal itu dapat dijelaskan bahwa untuk mahasiswa yang berusia muda, teman sebaya (peer) paling mendominasi pengambilan keputusan mereka.

Hasil penelitian ini dapat memberi masukan kepada HMJA dalam melaksanakan PSR selain AGTV, peran kebersamaan diantara relawan sangat besar, sehingga dapat menjadi pertimbangan untuk melaksanakan kegiatan lainnya. Sehingga untuk mengatasi permasalahan kurangnya minat para relawan untuk melaksanakan AGTV dapat diatasi dengan lebih banyak membuat program yang melibatkan mahasiswa sesame relawan.

Kekurangan penelitian ini adalah belum mengadakan wawancara dengan anak-anak yang di beri Pendidikan. Apakah mereka puas dengan kinerja relawan ataupun kurang puas. Sehingga untuk penelitain selanjutnya disarankan untuk mengadakan wawancara juga terhadap anak-anak yang menjadi objek kegiatan 


\section{REFERENSI}

Ahmad, Jamilah (2012) : Can a university act as a corporate social responsibility (CSR) driver? An analysis , Social Responsibility Journal, Vol 8 No 1, pp 7786.

Apejoye Adeyanju (2013) Influence of Celebrity Endorsement of Advertisement on Students' Purchase Intention J Mass Communicat Journalism 2013, 3:2

Carroll, A.B. (1999), "Corporate social responsibility', Business and Society, Vol. 38 No. 3, pp. 268-95.

Kolk A, Dolen, Vock M (2010) Trickle effects of cross- sector social partnership Journal of Business Ethics.

Miller C, Mc Intyre Shelby, Mantrala, Murali K (1993) : Toward formalizing fashion Theory, Vol xxx hal 142 - 57 Journal of Marketing Research

Matten Dirk, Moon Jeremy (2008) : Ïmplicit"and Ëxplicit CSR : a Conceptual framework for a comparative understanding of Corporate Social Responsibility. Academy of Management Review Vol. 33, No. 2, 404-424.

McCracken Grant (1986) Culture and Consumption: A Theoretical Account of the Structure and Movement of the Cultural Meaning of Consumer Goods, Journal Of Consumer Research Vol. 13. June

Mirvis Philip (2012) : Employee Engagement and CSR: Transactional, Relational and Developmental Approaches, California Management Review Vol 54 No 4 pp 93-117

Moon Jeremy (2004) Government as a Driver of Corporate Social Responsibility, Citeseer no 20
Vasilescua Ruxandra, Barnab C,Epurec, M, Baicud C (2010) : Developing university social responsibility:A model for the challenges of the new civil society, Procedia Social and Behavioral Sciences 2, 4177-4182 